\title{
Susceptibility to e-cigarette initiation among tobacco product naïve adolescents in Malaysia: Findings from the tobacco and e-cigarette survey among Malaysian adolescents (TECMA)
}

\author{
Pei Pei Heng',2, Faiz Daud', Muhammad F. Mohd Yusoffs, Kuang Hock Lim²
}

\begin{abstract}
INTRODUCTION Predicting susceptibility to e-cigarette (EC) initiation among adolescents is crucial to optimize preventive measures before the health risk behavior persists through adulthood. The identification of susceptible groups is needed in response to the surge of EC use. This study aimed to determine the prevalence and determinants associated with EC susceptibility among tobacco product naïve (never users of any single tobacco product) school-going adolescents in Malaysia.

METHOds Data were derived from the Tobacco and EC Survey among Malaysians (TECMA), which recruited a total of 13162 school-going adolescents aged 1019 years from 138 randomly selected schools via a two-stage stratified cluster sampling design. A validated self-administered questionnaire adapted from the Global Youth Tobacco Survey was utilized as the study instrument. The data were analyzed using SPSS version 22.0 descriptively and with multivariable logistic regression to determine the associated factors of EC susceptibility.

RESULTS About $15.7 \%$ of the tobacco naïve adolescents were susceptible to EC initiation, with the proportion of susceptibility significantly higher among males, mid-adolescents, rural adolescents, those reporting exposure to tobacco advertisement and those not taught in school about the danger of tobacco use. Multivariable logistic regression revealed that the male students $(\mathrm{AOR}=2.20$; 95\% CI: $1.86-2.59)$ from a rural locality (AOR=1.45; 95\% CI: $1.23-1.71)$, those reporting no lessons on the danger of tobacco use at school (AOR $=1.66 ; 95 \%$ CI: $1.39-1.99$ ) and those exposed to tobacco advertisement (AOR=1.67; 95\% CI: 1.07-2.61), were more susceptible to EC initiation, while no significant association was found between secondhand smoke exposure and EC susceptibility. ConcLusıons Comprehensive EC preventive strategies are critically needed together with the implementation of targeted, gender, and culturally impressionable interventions. In addition, future studies should focus on the evaluation of the impacts of the preventive and control efforts to ensure their effectiveness in preventing EC initiation among Malaysian adolescents.
\end{abstract}

AFFILIATION
1 Department of Community
Health, Faculty of Medicine,
National University of
Malaysia, Kuala Lumpur,
Malaysia
2 Institute for Public Health,
National Institutes of Health,
Setia Alam, Malaysia
3 Institute for Medical
Research, National Institutes
of Health, Setia Alam,
Malaysia

Malaysia

CORRESPONDENCE TO

Faiz Daud. Department of Community Health, Faculty of Medicine, National University of Malaysia, Jalan Yaacob Latif, Bandar Tun Razak, 56000 Kuala Lumpur, Malaysia.E-mail: faizdaud@ ppukm.ukm.edu.my ORCID ID: https://orcid. org/0000-0003-1405-5179

KEYWORDS susceptibility, e-cigarette initiation, tobacco naïve, school-going adolescents, TECMA

Received: 29 June 2021 Revised: 6 October 2021 Accepted: 6 October 2021

\section{INTRODUCTION}

The sale of nicotine e-liquids in Malaysia has been banned since 2015. Nevertheless, anti-tobacco legislation governing the sale and use of non-nicotine ECs is absent, to date. ECs of different brands, with or without nicotine, are widely accessible from the proliferated online stores without age gating to exclude minors ${ }^{1}$. Wong et al. ${ }^{2}$ reported that at least two-thirds of EC users in Selangor State were able to obtain nicotine e-liquid from EC retail, online 
stores, black market, and even self-made. National data documented a growing trend of EC use among school-going adolescents in the past decade $(3.9 \%$ in 2011 and $9.0 \%$ in 2016$)^{3}$, while a study targeted at school adolescents in the Federal Territory of Kuala Lumpur in 2019 reported $73 \%$ of EC users among the study population, which only purposively recruited users of conventional tobacco, ECs, and/or shisha in the past 30 days $^{4}$. The tobacco control landscape has been strengthened by preventive and control measures including smoke-free legislation, health warning labels, and prohibition of advertising, over the past three decades. Nevertheless, the increased social acceptability of ECs, which influences their use among adolescents might reverse public health efforts as well as renormalize smoking behavior.

The validated measure of 'susceptibility' established by Pierce et al. ${ }^{5}$ has been strongly associated with cigarette initiation longitudinally. The susceptibility predicted substance use after a year ${ }^{6}$. An experimental user eventually becomes an established user. The susceptibility construct, which was initially developed to identify risk groups toward future conventional cigarette use, has proven transferable to alternative tobacco products. The predictive validity of the susceptibility constructs to EC initiation among tobacco product naïve youth was reported to be high? . Moreover, a longitudinal study has documented the association between EC susceptibility with a higher than four times likelihood of future use $\mathrm{e}^{8,9}$. Hence, predicting the susceptibility to EC initiation among tobacco naïve adolescents is crucial to optimize effective preventive measures, as adolescence is a critical period for the development of health risk behaviors that will persist through adulthood.

Socio-environmental exposure and demographic factors are among the well-recognized determinants of susceptibility to EC initiation among adolescents in developed countries ${ }^{8,10}$. Understanding these determinants is of paramount importance in the advancement of tobacco control policy. Nevertheless, the predictors of susceptibility might be regionspecific, due to different socio-cultural backgrounds, norms, population characteristics, national legislation, and control measures. As a result, in-depth investigation of the correlates of EC susceptibility peculiar to Malaysian adolescents is critically needed in response to the surge of EC use among them.
Such knowledge will potentially guide policymakers, healthcare practitioners, and school authorities in the formulation of future national tobacco control strategies.

The robust relationship between EC susceptibility and future use necessitates the identification of susceptible adolescents before they try the first EC. A handful of studies across numerous countries primarily focused on the prevalence of EC use among existing users or ever users who had tried traditional cigarettes or alternative tobacco products ${ }^{11,12}$. Furthermore, existing local susceptibility studies are limited to conventional cigarette smoking among school adolescents ${ }^{13-15}$. The paucity of research on the susceptibility of EC initiation among tobacco product naïve Malaysian adolescents needs to be addressed. Thus, the aim of the present study is to determine the prevalence of EC susceptibility among tobacco product naïve school-going adolescents in Malaysia and the associated determinants of susceptibility, namely the sociodemographic factors, socioenvironmental exposure, and knowledge on tobaccorisk awareness provided at school. We hypothesized that males, older students, urban students, those reporting exposure to secondhand smoke (SHS) and to tobacco advertisements, would be more susceptible. On the other hand, tobacco-risk knowledge learned in school would be a protective factor.

\section{METHODS}

\section{Study design and sampling}

Data were analyzed from the nationwide crosssectional study of the Tobacco and E-Cigarette Survey among Malaysian Adolescents (TECMA) in 2016, which was designed to represent the schoolgoing adolescents aged 10-19 years at both public and private schools. The sampling frame included an updated database of primary (aged 7-12 years) and secondary schools (aged 13-19 years), which was provided by the Ministry of Education Malaysia. School-going adolescents from Standard four to Standard six (aged 10-12 years) in primary schools and Form one to Form six (aged 13-19 years) in secondary schools were the eligible participants. A two-stage stratified cluster sampling design was employed to ensure the representativeness of the samples. Malaysia was stratified into 15 states and by the school's urban status according to the definition 
of the Ministry of Education. In the first stage, schools (primary sampling unit) were selected in each state, taking into consideration the urban status, via systematic probability sampling proportional to the student enrolment size. The class (secondary sampling unit) selection at all selected schools was performed at the second stage utilizing a simple random sampling method. All students from the selected classes were recruited. A total of 138 schools ( 82 urban schools and 56 rural schools) and 537 classes were selected.

The sample size was determined by $4.7 \%$ of the estimated prevalence of EC used among Korean adolescents ${ }^{16}, 1.5 \%$ margin of error, $95 \%$ confidence interval, and a design effect of 1.5 to account for cluster effects and $20 \%$ expected non-response rate. Moreover, 13980 students were recruited with a total of 13162 students responding to the survey, yielding a response rate of $94.1 \%$. The ethical clearance and approval were obtained from the Ministry of Health Malaysia and the Ministry of Education Malaysia. Written informed consent was obtained from the respondents and parents/guardians before recruitment. Participation was on a voluntary basis with the privacy, anonymity and confidentiality of personal information ensured. The detailed methodology is described in Aris et al. ${ }^{17}$.

\section{Instrument and measures}

The TECMA study utilized a self-administered, standardized, structured, and validated questionnaire adapted from the Global Youth Tobacco Survey, World Health Organization. The tool has been translated into the local native language of Bahasa Melayu by a board of content and language experts, pre-tested among students of selected schools in the Federal Territory of Kuala Lumpur, and validated.

Being tobacco product naïve is defined as a never user of any single tobacco product. It excludes both the ever users and existing users. Only students that reported never experimenting with any of the substances listed (shisha, traditional hand-rolled cigarettes, tobacco cigarettes, cigars, pipe-smoking, ECs, chewing tobacco, and snuff) by answering 'No' to all sub-items were included in the data analysis.

The dependent outcome was susceptibility to EC initiation, which was measured by two validated items ${ }^{5,8}$ : 'If one of your best friends offered you an EC/vape, would you use it?' and 'At any time during the next 12 months, do you think you will use an EC/vape?'. The response choices for both items were: 'Definitely not', 'Probably not', 'Probably yes' and 'Definitely yes'. Only respondents who answered 'Definitely not' to both items were categorized as nonsusceptible; a combination of the other three answers in each item was classified as being susceptible to EC initiation.

The independent variables examined were sociodemographic factors, socio-environmental exposure, and knowledge on tobacco-risk provided at school. In the sociodemographic section, variables included gender (male and female), age group (1012 years, 13-15 years, and 16-19 years; thus, upper primary, lower secondary, and upper secondary school), locality (urban or rural), and ethnicity (Malay, Chinese, Indian, Bumiputera Sabah, Bumiputera Sarawak, and other). Under the socio-environmental exposure section, respondents were asked the total days exposed to SHS or secondhand EC aerosol at home, public areas, and at school in the past 7 days. Respondents who answered, '0 days' were categorized as non-exposed while those who gave answers other than '0 days' were considered exposed. Exposure to advertisements was measured with: 'Did you see any advertisements, messages and promotion of tobacco products at points-of-sale in the past 30 days' (Yes and attractive, Yes but not attractive, or No). Respondents also reported their knowledge of tobacco-risk via the item: 'Have you been taught in school about the danger of smoking' (Yes or No).

\section{Data management and analysis}

Data were cleaned and weighted based on the study design and non-response rate. All analyses were performed with SPSS version 22 statistical software with the results presented in $95 \%$ CI with $\mathrm{p}<0.05$ being statistically significant. The sociodemographic attributes were illustrated in frequency $(n)$ and percentage (\%), employing descriptive analysis. Pearson chi-squared analysis was employed to describe the association between susceptibility to EC initiation and all categorical independent variables. All the independent determinants with $\mathrm{p} \leq 0.25$ in univariate analysis were included in the model of multivariable logistic regression to determine the factors associated with EC susceptibility. The confounding effects were adjusted by clicking the 'Enter method' for all 
independent variables to determine the 'real effect' of each independent variable on the dependent outcome. A two-way interaction was examined between all independent variables in the final model. Adjusted odds ratios were then estimated and a $\mathrm{p}<0.05$ indicated a significant association.

\section{RESULTS}

Only respondents who reported to have never used any tobacco product were included in the analysis. Among 13162 respondents, 9696 (73.7\%) were naïve about tobacco products. The proportion of tobacco product naïve adolescents was significantly higher among females (58.6\%), those who were of Malay descent $(63.2 \%)$, adolescents aged $\leq 12$ years $(42.3 \%)$, and those who lived in rural localities (51.4\%) (Table $1)$.

The prevalence of EC susceptibility among the tobacco product naïve school-going adolescents was $15.7 \%$ (Table 2 ). The proportion of susceptible adolescents was two times higher among males (21.6\%, 95\% CI: 19.9-23.4) compared to females (11.1\%,95\% CI: 9.9-12.4). In addition, those from rural localities (16.6\%, 95\% CI: 15.0-18.3), Indians $(22.5 \%, 95 \%$ CI: $18.5-27.1)$, respondents

Table 1. Sociodemographic characteristics of tobacco product naïve participants ( $\mathrm{N}=9696)$

\begin{tabular}{|c|c|c|c|}
\hline Characteristics & $\begin{array}{l}\text { Estimated } \\
\text { population }\end{array}$ & $n$ & $\%$ \\
\hline \multicolumn{4}{|l|}{ Gender } \\
\hline Male & 1121290 & 3880 & 41.4 \\
\hline Female & 158904 & 5816 & 58.6 \\
\hline \multicolumn{4}{|l|}{ Ethnicity } \\
\hline Malay & 1147463 & 3419 & 63.2 \\
\hline Chinese & 413401 & 1512 & 15.3 \\
\hline Indian & 175414 & 612 & 6.5 \\
\hline Bumiputra Sabah & 142991 & 360 & 5.3 \\
\hline Bumiputra Sarawak & 151194 & 339 & 5.6 \\
\hline Other & 114320 & 288 & 4.2 \\
\hline \multicolumn{4}{|l|}{ Age (years) } \\
\hline$\leq 12$ & 1147643 & 3419 & 42.3 \\
\hline $13-15$ & 979938 & 3794 & 36.2 \\
\hline $16-19$ & 562748 & 2483 & 21.5 \\
\hline \multicolumn{4}{|l|}{ Locality } \\
\hline Urban & 1317735 & 5814 & 48.6 \\
\hline Rural & 1392595 & 3882 & 51.4 \\
\hline
\end{tabular}

Table 2. Susceptibility to e-cigarette among tobacco product naïve school-going adolescents in Malaysia $(\mathbf{N}=1523)$

\begin{tabular}{|c|c|c|c|c|}
\hline Variable & $\begin{array}{l}\text { Estimated } \\
\text { population }\end{array}$ & $n$ & $\%(95 \% \mathrm{CI})$ & $p$ \\
\hline Overall & 418105 & 1523 & $15.7(14.4-16.5)$ & \\
\hline \multicolumn{5}{|l|}{ Gender } \\
\hline Male & 241750 & 869 & $21.6(19.9-23.4)$ & $<0.001$ \\
\hline Female & 176354 & 654 & $11.1(9.9-12.4)$ & \\
\hline \multicolumn{5}{|l|}{ Ethnicity } \\
\hline Malay & 241004 & 947 & $14.1(12.8-15.5)$ & $<0.001$ \\
\hline Chinese & 85025 & 290 & $20.6(18.1-23.4)$ & \\
\hline Indian & 38952 & 133 & $22.5(18.5-27.1)$ & \\
\hline $\begin{array}{l}\text { Bumiputra } \\
\text { Sabah }\end{array}$ & 16146 & 48 & $11.3(8.1-15.5)$ & \\
\hline $\begin{array}{l}\text { Bumiputra } \\
\text { Sarawak }\end{array}$ & 17807 & 38 & $11.8(8.4-16.2)$ & \\
\hline Other & 18392 & 65 & $16.1(12.1-21.0)$ & \\
\hline \multicolumn{5}{|l|}{ Age (years) } \\
\hline$\leq 12$ & 172258 & 568 & $15.0(13.6-16.5)$ & 0.44 \\
\hline $13-15$ & 159820 & 607 & $16.4(14.5-18.3)$ & \\
\hline $16-19$ & 86025 & 348 & $14.8(12.7-17.2)$ & \\
\hline \multicolumn{5}{|l|}{ Locality } \\
\hline Urban & 187843 & 869 & $14.3(13.1-15.6)$ & 0.026 \\
\hline Rural & 230261 & 654 & $16.6(15.0-18.3)$ & \\
\hline \multicolumn{5}{|l|}{$\begin{array}{l}\text { Taught in } \\
\text { school about } \\
\text { the danger of } \\
\text { smoking }\end{array}$} \\
\hline Yes & 280430 & 996 & $12.5(12.4-14.7)$ & $<0.001$ \\
\hline No & 137675 & 527 & $22.0(19.7-24.4)$ & \\
\hline \multicolumn{5}{|l|}{$\begin{array}{l}\text { SHS exposure } \\
\text { at home }\end{array}$} \\
\hline Yes & 130814 & 464 & $15.0(13.2-16.9)$ & 0.527 \\
\hline No & 287291 & 1059 & $15.7(14.5-17.0)$ & \\
\hline Yes & 225839 & 819 & $15.3(14.0-16.7)$ & 0.731 \\
\hline No & 192265 & 704 & $15.7(14.1-17.3)$ & \\
\hline \multicolumn{5}{|l|}{$\begin{array}{l}\text { SHS exposure } \\
\text { at school }\end{array}$} \\
\hline Yes & 269567 & 985 & $17.3(15.7-19.1)$ & 0.012 \\
\hline No & 147441 & 534 & $14.6(13.4-16.0)$ & \\
\hline \multicolumn{5}{|l|}{$\begin{array}{l}\text { Exposure to } \\
\text { advertisements, } \\
\text { messages, and } \\
\text { promotions at } \\
\text { the point-of- } \\
\text { sale }\end{array}$} \\
\hline No & 275506 & 1009 & $15.9(14.7-17.2)$ & 0.003 \\
\hline $\begin{array}{l}\text { Yes (not } \\
\text { attractive) }\end{array}$ & 130250 & 467 & $14.0(12.3-16.0)$ & \\
\hline Yes (attractive) & 12135 & 46 & $27.0(19.5-35.9)$ & \\
\hline
\end{tabular}


who reported not been taught in school about the danger of tobacco use $(22.0 \%$, 95\% CI: $19.2-24.4)$, those who reported exposed to SHS at school in the past week (17.3\%, 95\% CI: 15.7-19.1), as well as respondents who reported positive exposure toward tobacco advertisement at the point-of-sale and perceived it as attractive (17.0\%, 95\% CI: 19.5-35.9), had significantly higher EC susceptibility. However, there was no significant association found between SHS exposure at home and at public places, with EC susceptibility.

After confounders were adjusted for in the multivariable logistic regression analysis (Table 3 ), males (AOR=2.20; 95\% CI: 1.86-2.59), Indian

Table 3. Multivariable logistic regression analysis to determine factors associated with EC susceptibility $(\mathbf{N}=9368)$

\begin{tabular}{|c|c|c|c|c|}
\hline Variable & AOR & $95 \% \mathrm{CI}$ & $x^{2}$ & $p$ \\
\hline \multicolumn{5}{|l|}{ Gender } \\
\hline Male & 2.20 & $1.86-2.59$ & $87.10^{\mathrm{a}}$ & $<0.01^{* *}$ \\
\hline Female & 1.00 & & & \\
\hline \multicolumn{5}{|l|}{ Ethnicity } \\
\hline Malay & 1.00 & & $4.00^{b}$ & \\
\hline Chinese & 1.36 & $1.11-1.66$ & & $<0.01^{* *}$ \\
\hline Indian & 1.39 & $1.05-1.83$ & & \\
\hline Bumiputra Sabah & 0.72 & $0.49-1.09$ & & \\
\hline Bumiputra Sarawak & 0.74 & $0.50-1.10$ & & \\
\hline Other & 1.13 & $0.80-1.60$ & & \\
\hline \multicolumn{5}{|l|}{ Locality } \\
\hline Urban & 1.00 & & $20.19^{a}$ & $<0.05^{*}$ \\
\hline Rural & 1.45 & $1.23-1.71$ & & \\
\hline \multicolumn{5}{|c|}{$\begin{array}{l}\text { Taught in school about } \\
\text { the danger of smoking }\end{array}$} \\
\hline Yes & 1.00 & & $31.49^{\mathrm{a}}$ & $<0.001^{* * *}$ \\
\hline No & 1.66 & $1.39-1.99$ & & \\
\hline \multicolumn{5}{|l|}{$\begin{array}{l}\text { Exposure to } \\
\text { advertisements, } \\
\text { messages, and } \\
\text { promotions at the } \\
\text { point-of-sale }\end{array}$} \\
\hline No & 1.00 & & $3.49^{b}$ & $<0.01^{* *}$ \\
\hline Yes (not attractive) & 0.90 & $0.75-1.08$ & & \\
\hline Yes (attractive) & 1.67 & $1.07-2.61$ & & \\
\hline \multicolumn{5}{|c|}{ SHS exposure at school } \\
\hline Yes & 0.93 & $0.79-1.09$ & $0.80^{\mathrm{a}}$ & 0.321 \\
\hline No & 1.00 & & & \\
\hline
\end{tabular}

AOR: adjusted odds ratio. a Likelihood ratio test. b Wald test. descent $(\mathrm{AOR}=1.39 ; 95 \%$ CI: 1.05-1.83) followed by Chinese descent $(\mathrm{AOR}=1.36$; 95\% CI: 1.11-1.66), respondents from a rural locality $(\mathrm{AOR}=1.45 ; 95 \% \mathrm{CI}$ : 1.23-1.71), those who reported not been taught on the danger of tobacco use at school $(\mathrm{AOR}=1.66 ; 95 \%$ CI: 1.39-1.99) and students who reported attractive positive exposure to tobacco advertisement at the point-of-sale $(\mathrm{AOR}=1.67 ; 95 \% \mathrm{CI}: 1.07-2.61)$, were more likely to have EC susceptibility.

\section{DISCUSSION}

This is the first study that evaluated EC susceptibility among the tobacco product naïve school-going adolescents in Malaysia, employing a nationally representative sample. The prevalence of EC susceptibility among the Malaysian tobacco product naïve adolescents was $15.7 \%$, comparable to Florida, US, youth $(14.2 \%)^{18}$ and Canadian adolescents $(13.6 \%)^{7}$. Our finding is lower compared to a number of regions in the US which reported a range of EC susceptibility of $24-45 \%{ }^{8,19,20}$, to rural Appalachia with $29.1 \%^{21}$, and rural Poland with $68 \%{ }^{22}$. However, our prevalence was much higher than reported in North Carolina $(11.3 \%)^{23}$, and Hong Kong $(7 \%)^{12}$. The discrepancies in susceptibility prevalence might be due to cultural differences and socio-norm variations across nations. The difference in the conceptualization and definition of tobacco product naïve and EC susceptibility may have addressed the susceptibility prevalence dissimilarly ${ }^{24}$. Individual respondents from dissimilar socio-cultural backgrounds perceived smoking susceptibility differently. Furthermore, the different age ranges of respondents recruited might have contributed to the disparity in the cross-national prevalences. The current study recruited adolescents aged 10-19 years, as defined by the World Health Organization. Nevertheless, the age group of 13-17 years was studied in Hong Kong ${ }^{12}$, those aged 14-17 years were recruited for the study in Florida ${ }^{18}$ while only adolescents aged 14-15 years were involved in a study in rural Appalachia ${ }^{21}$. Other determinants influencing the susceptibility prevalence include attainment in national initiatives of tobacco control policy and the influence of the tobacco industry. For example, more than half of the South-East Asian countries, including Malaysia, have banned the use of nicotine ECs since 2009; however, western countries like United Kingdom, New Zealand, and some 
European countries, permit nicotine EC marketing ${ }^{25}$.

The odds of EC susceptibility were significantly higher among males compared to females, which were three times higher among the lower secondary group, and almost two times higher among the upper secondary and upper primary groups. This finding is in accordance with those reported by Bold et al. ${ }^{8}$, Dai and $\mathrm{Hao}^{26}$, and Saddleson et al. ${ }^{27}$ in which the boys typically perceived lower risk and, therefore, more likely to indulge in high-risk behavior compared to girls. The adolescents' tobacco use behaviors were built upon the gender dimension, given the variations in underlying neurobiological mechanisms and metabolism between males and females ${ }^{28}$. The testosterone levels among males surge during the puberty stage from an average age of 13 years, which corresponds to the development of psychological characteristics including addictive, risk-taking, and pleasure motivated behavior, via the activation of dopamine release from the brain. On the other hand, the gradually developing cognitive control system along with the maturation imbalance model which leads to the limitation of impulse restrain for sensation seeking $^{29}$, may best explain why risky situations and potentially harmful impulses are induced specifically among males. In addition, social studies have also substantiated that cultural and social networks highly influence tobacco adoption behaviors across gender. The Malaysian traditional social norms rigidly restrict women's tobacco use, and hence have contributed to the social disapproval of female smokers or vapers. These gender expectations among the Malaysian community explained the findings from several local studies that male adolescents were more likely to use $\mathrm{ECs}^{3}$ as well as being more susceptible to conventional cigarette $\mathrm{use}^{15}$. Therefore, the tobacco control interventions aiming to combat the adolescent vaping epidemic should be gender-specific, recognizing the importance of gender variations in the mechanism of EC initiation and transition, rather than a genderblind approach.

Comparable to the national study among youth aged 11-17 years in the US ${ }^{30}$, our study similarly reported that rural adolescents have higher odds of EC susceptibility. This finding is, however, in contrast to a Korean study among middle and high school adolescents ${ }^{31}$ and a study among Malaysian university youth which reported significant EC use among the urban dwellers due to accessibility to EC sources, which enhances interest in EC use ${ }^{25}$. Malaysia has rigorously enforced an anti-smoking strategy nationwide with the expansion of a tobacco ban in all eateries, effective from January 2020. Nevertheless, the standardized implementation of tobacco control measures across urban and rural settings might be a huge challenge, due to the lack of trained health and environmental officers in rural settings. As a result, the lack of awareness, in addition to distress from economic and social determinants of health, has created a high-risk environment that predisposes the undeserved rural youth to tobacco product use including $\mathrm{EC}^{22}$. Moreover, numerous studies focused solely among tobacco naïve adolescents in disadvantaged rural areas have documented a high proportion of EC susceptibility in rural Appalachia $(29.1 \%)^{21}$ and rural Poland $(68 \%)^{22}$. We propose that these rural populations were characterized by lower health index and were inadequately covered by intervention, educational measures, or comprehensive scientific research. This highlights the necessity for future epidemiological investigation of differences in the associated factors of tobacco use between urban and rural areas.

Being taught in school about the hazardous impacts of tobacco use was identified as a protective factor against EC susceptibility, which was in line with the findings of smoking susceptibility among Malaysian adolescents ${ }^{15}$ and those reported in Gambia ${ }^{32}$. Education positively influences the awareness of adolescents about the dangers associated with EC use. On the other hand, the theory of planned behavior supports the notion that an individual's perception may influence specific behavioral participation ${ }^{33}$. Therefore, the perception of risk or harm is shaped by educational exposure and determines health behavior decision-making which supports the significance of knowledge-based school interventions ${ }^{34}$.

EC susceptibility was $67 \%$ higher among Malaysian adolescents exposed to tobacco advertisement at the point-of-sale who reported it as attractive, which is in line with a longitudinal study which reported that such exposure predicted susceptibility to EC initiation after 6 months $^{35}$. Through the advertising tactic of the tobacco industry based on hierarchy-of-effects models, the EC advertisement makes the target group aware and develops receptivity toward EC, and finally 
influences their consumption behavior ${ }^{36,37}$. ECs are frequently being marketed as glamorous and healthful to increase curiosity and initiation among youth who never use EC. The advertisements extensively work via the unconscious route to alter the harm perception during adolescents' behavioral decisions, and this evidence was strengthened via meta-analysis which confirmed the significant relationship between EC advertisements and reduced-risk perception of occasional tobacco use ${ }^{38}$. High-intensity EC marketing has been effectively banned. Nevertheless, small-scale promotions are available in local or online stores. Therefore, the impact of EC advertisements at pointof-sale demands deliberation from policymakers, as tolerant attitudes toward ECs following advertisement exposure may lead to negative attitudes toward antitobacco policies. The future regulatory framework ought to revise the restriction on EC promotion at point-of-sale, and also to remove the distribution of EC retail outlets around areas of educational institutions, to minimize the contact between adolescents and tobacco marketing.

The present study also discovered a higher EC susceptibility among adolescents of Indian descent (39\% higher) and Chinese descent (36\% higher). We postulate that the high-volume EC promotions were more profuse in the predominantly Indian and Chinese neighborhoods, most likely secondary to cultural and religious influences. Malaysia is a multiracial country with the most of the population being Muslims and tobacco usage is prohibited under the Islamic legal pronouncement of Tobacco Fatwa ${ }^{39}$. On the other hand, a local study by Lim et al. ${ }^{15}$ also observed a higher susceptibility to conventional cigarette smoking among Indian adolescents. These sociodemographic factors need to be considered while developing tailored preventive educational measures ${ }^{34}$. Therefore, future research needs to explore racial and ethnic behavioral risk factors as well as the qualitative social norms related to intervention, to disentangle racial factors for effective preventive measures.

In contrast to individual studies that reported a significant association between EC susceptibility and SHS exposure at home or public areas ${ }^{19,26}$, our study found no association. The pro-tobacco environment with EC use among the household members or public could raise the perceived social acceptability, therefore placing adolescents at greater risk of EC susceptibility. In line with this, one local study by Lim et al. ${ }^{15}$ had highlighted the higher conventional smoking susceptibility among adolescents who reported exposure to SHS in public areas. The differences between the study of Lim et al. ${ }^{15}$ and the present study suggest that adolescents who are attracted to ECs might be different from those who are attracted to other types of tobacco products ${ }^{40}$, which indicates the practicality of tailored preventive strategies based on specific tobacco products. Our study only recruited school-going subjects; while adolescents who have dropped out of school were not assessed, therefore this might be another plausible reason for the non-significant findings between SHS exposure and EC susceptibility. The association between environmental SHS exposure and EC susceptibility requires further research, especially after Malaysia expanded the legislative tobacco products bans in all eateries in January 2020.

\section{Limitations}

Several limitations have been identified in the present study. First, the cross-sectional design has limited the causal inferences between EC susceptibility and the independent determinants. Second, the self-reported data collection may be subject to recall bias and even reporting bias, as pro-tobacco behavior is not socially acceptable by local norms. Besides, some of the determinants of susceptibility in the adapted questionnaire were only assessed by a single-item measure. Indicators like intrapersonal psychological factors, substance abuse, and parental and peer influence were not evaluated in the study.

\section{CONCLUSIONS}

More than one in ten of tobacco naïve school-going adolescents were susceptible to EC. The Malaysian current regulatory ban only covers nicotine ECs, and excludes non-nicotine ECs, while vaping products remain widely accessible in the proliferated online stores. A more comprehensive EC legislative control is critically needed to minimize EC exposure among adolescents. In addition, the implementation of targeted, comprehensive, gender, and culturally impressionable school and community-based interventions, are essential. Future studies should also focus on the evaluation of the impact of preventive and control measures to ensure their effectiveness in restricting EC initiation among Malaysian adolescents. 


\section{REFERENCES}

1. Jackler RK, Li VY, Cardiff RA, Ramamurthi D. Promotion of tobacco products on Facebook: policy versus practice. Tob Control. 2019;28:67-73. doi:10.1136/tobaccocontrol-2017-054175

2. Wong LP, Alias H, Agha Mohammadi N, Ghadimi A, Hoe VCW. E-Cigarette Users' Attitudes on the Banning of Sales of Nicotine E-Liquid, Its Implication on E-Cigarette Use Behaviours and Alternative Sources of Nicotine E-Liquid. J Community Health. 2017;42(6):1225-1232. doi:10.1007/s10900-017-0374-z

3. Robert Lourdes TG, Abd Hamid HA, Mohd Yusoff MF, et al. Factors Associated With E-Cigarette Usage and the Reasons for Initiation Among Malaysian Adolescents. Asia Pac J Public Health. 2019;31(7_suppl):44S-52S. doi:10.1177/1010539519870663

4. Nur Atikah AH, Wee LH, Nur Zakiah MN, et al. Factors associated with different smoking statuses among Malaysian adolescent smokers: a crosssectional study. BMC Public Health. 2019;19(S4):1-8. doi:10.1186/s12889-019-6857-3

5. Pierce JP, Choi WS, Gilpin EA, Farkas AJ, Merritt RK. Validation of susceptibility as a predictor of which adolescents take up smoking in the United States. Health Psychol. 1996;15(5):355-361. doi:10.1037//0278-6133.15.5.355

6. Pierce JP, Sargent JD, Portnoy DB, et al. Association Between Receptivity to Tobacco Advertising and Progression to Tobacco Use in Youth and Young Adults in the PATH Study. JAMA Pediatr. 2018;172(5):444-451. doi:10.1001/jamapediatrics.2017.5756

7. Cole AG, Kennedy RD, Chaurasia A, Leatherdale ST. Exploring the predictive validity of the susceptibility to smoking construct for tobacco cigarettes, alternative tobacco products, and E-cigarettes. Nicotine Tob Res. 2019;21(3):323-330. doi:10.1093/ntr/ntx265

8. Bold KW, Kong G, Cavallo DA, Camenga DR, KrishnanSarin S. E-cigarette susceptibility as a predictor of youth initiation of e-cigarettes. Nicotine Tob Res. 2017;20(1):140-144. doi:10.1093/ntr/ntw393

9. Nicksic NE, Barnes AJ. Is susceptibility to E-cigarettes among youth associated with tobacco and other substance use behaviors one year later? Results from the PATH study. Prev Med. 2019;121:109-114. doi:10.1016/j.ypmed.2019.02.006

10. Case KR, Harrell MB, Pérez A, et al. The relationships between sensation seeking and a spectrum of e-cigarette use behaviors: cross-sectional and longitudinal analyses specific to Texas adolescents. Addict Behav. 2017;73:151157. doi:10.1016/j.addbeh.2017.05.007

11. Hammig B, Daniel-Dobbs P, Blunt-Vinti H. Electronic cigarette initiation among minority youth in the United States. Am J Drug Alcohol Abuse. 2017;43(3):306-310. doi:10.1080/00952990.2016.1203926

12. Wang L, Chen J, Ho SY, Leung LT, Wang MP, Lam TH. Exposure to e-cigarette advertising, attitudes, and use susceptibility in adolescents who had never used e-cigarettes or cigarettes. BMC Public Health. 2020;20(1):1-9. doi:10.1186/s12889-020-09422-w

13. Hock LK, Ghazali SM, Cheong KC, et al. Correlates of susceptibility to smoking among secondary school students in Kota Tinggi district, Johor, Malaysia. Asian Pac J Cancer Prev. 2013;14(11):6971-6978. doi:10.7314/apjcp.2013.14.11.6971

14. Lim KH, Chong Z, Khoo YY, Kaur J. Parental smoking status, stress, anxiety, and depression are associated with susceptibility to smoking among nonsmoking school adolescents in Malaysia. Asia Pacific Journal of Public Health. 2014;26(5_suppl):81S-90S. doi:10.1177/1010539514542426

15. Lim KH, Ghazali SM, Lim HL, et al. Smoking susceptibility among non-smoking school-going adolescents in Malaysia: findings from a national school-based survey. BMJ Open. 2019;9(10):e031164. doi:10.1136/bmjopen-2019-031164

16. Lee S, Grana RA, Glantz SA. Electronic cigarette use among Korean adolescents: a cross-sectional study of market penetration, dual use, and relationship to quit attempts and former smoking. J Adolesc Health. 2014;54(6):684690. doi:10.1016/j.jadohealth.2013.11.003

17. Institute for Public Health. Tobacco \& E-Cigarette Survey Among Malaysian Adolescents (TECMA). Institute for Public Health; 2016. Accessed June 29, 2021. https:// iku.moh.gov.my/images/IKU/Document/REPORT/ TECMA2016/TabaccoandECigarette.pdf

18. Bernat D, Gasquet N, Wilson KO, Porter L, Choi K. Electronic Cigarette Harm and Benefit Perceptions and Use Among Youth. Am J Prev Med. 2018;55(3):361-367. doi:10.1016/j.amepre.2018.04.043

19. Kwon E, Seo DC, Lin HC, Chen Z. Predictors of youth e-cigarette use susceptibility in a US nationally representative sample. Addict Behav. 2018;82:79-85. doi:10.1016/j.addbeh.2018.02.026

20. Wang TW, Gentzke AS, Creamer MR, et al. Tobacco product use and associated factors among middle and high school students-United States, 2019. MMWR Surveill Summ. 2019;68(12):1-22. doi:10.15585/mmwr.ss6812a1

21. Mamudu HM, Nwabueze C, Weierbach FM, et al. Exploring Associations between Susceptibility to the Use of Electronic Nicotine Delivery Systems and E-Cigarette Use among School-Going Adolescents in Rural Appalachia. Int J Environ Res Public Health. 2020;17(14):5133. doi:10.3390/ijerph17145133

22. Kaleta D, Niedzin M, Jankowska A, Polańska K. Predictors of E-cigarette use susceptibility-A study of young people from a socio-economically disadvantaged rural area in Poland. Int J Environ Res Public Health. 2019;16(20):3935. doi:10.3390/ijerph16203935

23. Kowitt SD, Osman A, Ranney LM, Heck C, Goldstein AO. E-cigarette use among adolescents not susceptible 
to using cigarettes. Prev Chronic Dis. 2018;15. doi:10.5888/pcd15.170368

24. Lim KH, Lim HL, Teh CH, et al. Smoking among school-going adolescents in selected secondary schools in peninsular Malaysia-findings from the Malaysian adolescent health risk behaviour (MyaHRB) study. Tob Induc Dis. 2017;15(January):1-8. doi:10.1186/s12971-016-0108-5

25. Puteh SEW, Manap RA, Hassan TM, et al. The use of e-cigarettes among university students in Malaysia. Tob Induc Dis. 2018;16(December). doi:10.18332/tid/99539

26. Dai H, Hao J. Exposure to Advertisements and Susceptibility to Electronic Cigarette Use Among Youth. J Adolesc Health. 2016;59(6):620-626. doi:10.1016/j.jadohealth.2016.06.013

27. Saddleson ML, Kozlowski LT, Giovino GA, et al. Risky behaviors, e-cigarette use and susceptibility of use among college students. Drug Alcohol Depend. 2015;149:25-30. doi:10.1016/j.drugalcdep.2015.01.001

28. Schmidt HD, Rupprecht LE, Addy NA. Neurobiological and neurophysiological mechanisms underlying nicotine seeking and smoking relapse. Mol Neuropsychiatry. 2018;4(4):169-189. doi:10.1159/000494799

29. Dick B, Ferguson BJ. Health for the world's adolescents: a second chance in the second decade. J Adolesc Health. 2015;56(1):3-6. doi:10.1016/j.jadohealth.2014.10.260

30. Pesko MF, Robarts AM. Adolescent tobacco use in urban versus rural areas of the United States: the influence of tobacco control policy environments. J Adolesc Health. 2017;61(1):70-76. doi:10.1016/j.jadohealth.2017.01.019

31. Park S, Lee H, Min S. Factors associated with electronic cigarette use among current cigarette-smoking adolescents in the Republic of Korea. Addict Behav. 2017;69:22-26. doi:10.1016/j.addbeh.2017.01.002

32. Jallow IK, Britton J, Langley T. Prevalence and determinants of susceptibility to tobacco smoking among students in the Gambia. Nicotine Tob Res. 2019;21(8):1113-1121. doi:10.1093/ntr/nty128

33. Montano DE, Kasprzyk D. Theory of reasoned action, theory of planned behavior, and the integrated behavioral model. Health behavior: Theory, research and practice. 2015;70(4).

34. Pfeiffer JA, Tompkins LK, Hart JL, et al. Relationship between population characteristics, e-cigarette and tobacco-related perceptions, and likelihood of ever using e-cigarettes. Tob Prev Cessat. 2020;6(March). doi:10.18332/tpc/117477

35. Nicksic NE, Harrell MB, Pérez A, Pasch KE, Perry CL. Recall of E-cigarette Advertisements and Adolescent E-cigarette Use. Tob Regul Sci. 2017;3(2):210-221. doi:10.18001/TRS.3.2.9

36. Barry TE, Howard DJ. A review and critique of the hierarchy of effects in advertising. Int J Advert. 1990;9(2):121-135. doi:10.1080/02650487.1990.11107138

37. Abd Wahil MS, Nor SFS, Mun WC, et al. Visitors'
Perception of the Effectiveness of Leptospirosis Health Hazard Warning Signage in Recreational Parks, Hulu Langat District, Malaysia. ASM Science Journal. 2021;14. doi:10.32802/asmscj.2020.653

38. Petrescu DC, Vasiljevic M, Pepper JK, Ribisl KM, Marteau TM. What is the impact of e-cigarette adverts on children's perceptions of tobacco smoking? An experimental study. Tob Control. 2017;26(4):421-427. doi:10.1136/tobaccocontrol-2016-052940

39. Juni MH. Tobacco Use Is Prohibited (Haram) in Islam. International Journal of Public Health and Clinical Sciences. 2014;1:19-28. Accessed June 29, 2021. http:// www.publichealthmy.org/ejournal/ojs2/index.php/ ijphcs/article/view/111

40. Hyeon J H, Shelley C, Lee CM. Prevalence and correlates of prior experimentation with e-cigarettes over conventional cigarettes among adolescents: Findings from the 2015 Korea Youth Risk Behaviour Webbased Survey. Tob Prev Cessation. 2019;5(October). doi:10.18332/tpc/112595

\section{ACKNOWLEDGEMENTS}

We thank the Director-General of Health Malaysia for the permission to publish this article. We also thank all authorities involved in the survey, as well as the Department of Community Health, Faculty of Medicine, National University of Malaysia, for their support.

\section{CONFLICTS OF INTEREST}

The authors have each completed and submitted an ICMJE form for disclosure of potential conflicts of interest. The authors declare that they have no competing interests, financial or otherwise, related to the current work. F. Daud reports receiving funding from Universiti Kebangsaan Malaysia, and that the Malaysian Ministry of Health allowed the data collection and presentation.

\section{FUNDING}

The research was funded by the Ministry of Health Malaysia and the Universiti Kebangsaan Malaysia.

\section{ETHICAL APPROVAL AND INFORMED CONSENT}

Ethical approval was obtained from the Ministry of Health Malaysia, Medical Research Ethics Committee (Approval: NMRR-20-3149-57296 IIR; 6 May 2021); and from the Universiti Kebangsaan Malaysia, Ministry of Education (Approval: FF-2021-210 (UKM PPI/111/8/JEP-2021-367); 24 May 2021). Written informed consent was obtained from the participants and their parents/guardians before recruitment.

\section{DATA AVAILABILITY}

The data supporting this research are available from the authors on reasonable request.

\section{AUTHORS' CONTRIBUTIONS}

FD coordinated the study and performed the quality assurance. MFMY designed the research. PPH wrote the manuscript. PPH and KHL were involved in data management and statistical analysis. All authors were involved in the interpretation and implications of the data, reviewed the draft manuscript and agreed upon the final version.

PROVENANCE AND PEER REVIEW

Not commissioned; externally peer reviewed. 